\title{
Culpa CONCURRENTE DE LA VÍCTIMA Y DAÑO POR REBOTE O REPERCUSIÓN
}

[Contributory negligence and damages for indirect victims]

\author{
Lilian C. San Martín Neira*
}

\section{RESUMEN}

Este artículo analiza la relación entre las instituciones de culpa concurrente de la víctima y daño por rebote o repercusión. En particular, se refiere a dos series de casos: cuando la víctima directa incurre en culpa y cuando la víctima directa es un incapaz sujeto al cuidado de quien actúa como víctima por rebote. En ambos casos se analiza la posibilidad de que la indemnización de la víctima por rebote sea ajustada sobre la base de la culpa concurrente. En el primero, a raíz de la culpa concurrente de la víctima directa; en el segundo, a raíz de la culpa propia. Asimismo, tratándose de las víctimas incapaces, se analiza la posibilidad de traspasar a

\begin{abstract}
This article examines the relationship between the institutions of contributory negligence and the damages entitled by the indirect victims. In particular, refers to two series of cases: when the direct victim incurs in contributory negligence and when the direct victim is an incapable subject to the care of those who are also indirect victims. In both cases, the paper explores the possibility of that compensation to the indirect victim would be adjusted on the basis of the contributory negligence, in the first case, as a result of the concurrent fault of the direct victim and, in the second one, as a result of its own fault. Furthermore, in cases of incapable victims, the article
\end{abstract}

RECIBIDO el 7 de noviembre y APROBADO el 31 diciembre de 2016

* Profesora de Derecho civil, Universidad Alberto Hurtado. Dirección postal: Cienfuegos 41, Santiago de Chile. Correo electrónico: 1sanmar@uahurtado.cl. Este trabajo forma parte del proyecto Fondecyt Iniciación, 11140246, del cual la autora es investigadora responsable. 
estas la culpa concurrente del guardián y la situación en que quedan las demás víctimas por rebote cuando el daño del incapaz se ha producido a raíz de la culpa concurrente del guardián. En todas las hipótesis analizadas se tiene en especial consideración la institución de la solidaridad derivada de la responsabilidad extracontractual, pues se considera que en ella está la clave para una adecuada inteligencia de los problemas enfrentados.

\section{Palabras clave}

Culpa concurrente de la víctima - víctimas por rebote - daño por repercusión - solidaridad. discusses the possibility of transferring de contributory negligence of the guardian to the direct victim and the situation in which are the other indirect victims when the accident has happened because of the guardian's fault. In all those cases, the article specially considers the institution of solidarity derived from the tort, because the author considers that this is a crucial point on this matter.

\section{KEYWORDS}

Contributory negligence - indirect victims - damages for the indirect victims - solidarity.

\section{LA CULPA DE LA VÍCTIMA DIRECTA COMO CAUSAL DE DISMINUCIÓN DEL DAÑO POR REBOTE}

\section{Planteamiento de la cuestión: propuestas doctrinarias de justificación} de la reducción de la indemnización

Una de las discusiones clásicas en torno a la culpa concurrente de la víctima ha sido la posibilidad de oponer la culpa de la víctima directa a las víctimas por rebote o repercusión ${ }^{1}$. En este sentido, tradicionalmente

${ }^{1}$ Un excelente resumen de las distintas posiciones al respecto se encuentra en: Corte de Apelaciones de Concepción, 15 de abril de 2011, Rol № 1495-2010. En doctrina, vid AlesSANDri RodrígueZ, Arturo, De la responsabilidad extracontractual en el derecho chileno (Santiago, Imprenta Universitaria, 1943), p. 576; DOMíngueZ ÁGUILA, Ramón, El hecho de la víctima como causal de exoneración de responsabilidad civil, en Revista de Derecho Universidad de Concepción, 136 (1966), pp. 47 ss.; DíEZ SChWerter, José Luis, El daño extracontractual (Santiago, Editorial Jurídica de Chile, 1997), pp. 236 ss.; ElORRIAGA De Bonis, Fabián, El daño por repercusión o rebote, en Revista Chilena de Derecho 26 (1999) 2, pp. 390 ss.; Domínguez Águila, Ramón, Inaplicabilidad de la responsabilidad subsidiaria laboral en la acción extracontractual civil. Inoponibilidad de la culpa de la víctima a las víctimas por repercusión o rebote, en Revista de Derecho Universidad de Concepción, 215-216 (2004), pp. 360 ss.; Barros Bourie, Enrique, Tratado de responsabilidad extracontractual (Santiago, Editorial Jurídica de Chile, 2006), pp. 438 ss.; Bahamondes O. Claudia, Pizarro W., Carlos, La exposición imprudente de la víctima al daño desde la culpabilidad a la causalidad, en Revista de Derecho de la Pontificia Universidad Católica de Valparaiso, No XXXIX (2012), pp. 49 ss.; CoRral TAlCIANI, Hernán, Lecciones de responsabilidad extracon- 
se han distinguido dos situaciones: (i) si los demandantes actúan como herederos de la víctima, procedería la reducción; (ii) si los demandantes actúan a título personal, no procedería la reducción. El fundamento de esta última solución es la au tono mía del daño por repercusión. Sin embargo, la doctrina nacional moderna se ha alineado en torno a la procedencia de la reducción, independientemente de a qué título demande la víctima indirecta ${ }^{2}$, incluso se ha llegado a señalar que tal distinción resulta "artificiosa"3. En esta línea de pensamiento, lo más difícil ha sido encontrar las justificaciones dogmáticas que, al margen de válidas razones de justicia y/o equidad, autoricen tal reducción. En efecto, si bien existe una intrínseca relación entre el daño directo y el daño por rebote, no es menos cierto que éste último constituye un daño en sí mismo, diferenciable del daño de la víctima y respecto del cual se aplican todos los principios y reglas de la responsabilidad civil, comenzando por el principio de resarcimiento integral del daño, cuyas limitaciones deben interpretarse restrictivamente ${ }^{4}$. Así, resulta necesario individualizar reglas que, al interior del sistema de responsabilidad, autoricen para excluir parcialmente el resarcimiento de las víctimas por rebote. Este es uno de los objetivos del presente trabajo.

Atendida la importancia práctica del argumento, los autores nacionales han realizado esfuerzos dirigidos a justificar la oponibilidad de la culpa de la víctima directa a las víctimas por rebote. Cronológicamente, el primero corresponde a Domínguez Águila, quien se ha referido al punto en dos artículos escritos con casi cuarenta años de diferencia. En el primero, de 1966, el autor identifica como principal razón para aplicar la reducción al caso en análisis la interdependencia entre los daños de la víctima directa y por rebote, al efecto afirma que el daño de la víctima directa está estrechamente ligado al de la víctima por rebote, por ejemplo, en caso de muerte, "si aquella no hubiera perecido, de nada habría podido quejarse este último" . A eso, sostiene, debe agregarse "el hecho de que es invocando ciertos vínculos que unen al actor con la víctima, que aquél puede pretender una acción reparadora del perjuicio. Sin esos lazos o re-

tractual (2a ed., Santiago, LegalPublishing, 2013), pp. 199 ss.; WeGner A., Verónica, ¿Es verdaderamente la acción de la víctima por repercusión o rebote una acción autónoma e independiente?, en Turner Saelzer, Susan y Varas Braun, Juan Andrés (coordinadores), Estudios de derecho civil IX (Santiago, LegalPublishing - Thomson Reuters, 2014), pp. 743 ss.

2 Vid supra, doctrina citada en nota 1.

${ }^{3}$ Barros Bourie, cit. (n. 1), p. 439.

${ }^{4}$ Vid Domínguez Águila, Ramón, Los límites al principio de reparación integral, en Revista Chilena de Derecho Privado 15 (2010), pp. 9-28.

5 Domínguez Águila, El hecho de la víctima, cit. (n. 1), p. 52. 
laciones no se tiene derecho a acción alguna, pues los perjuicios resultan justamente de dichas relaciones. Es porque el causahabiente es hijo, padre, hermano, etc., que puede pretender haber sufrido un daño con la muerte de la víctima directa" "Se trataría de un vínculo indisoluble, que no puede ser invocado para demandar reparación y negado a la hora de establecer los perjuicios derivados del accidente en que ha tomado participación la víctima ${ }^{7}$. En el segundo texto, de 2004, el autor agrega como argumento la causalidad, afirmando que "no es posible dividir el hecho causal de los daños directos y por repercusión. El origen de ambos daños es uno mismo: el hecho que causó la muerte o la lesión de la víctima directa y aquel hecho tiene como causa, tanto el accidente del demandado, como la culpa de la víctima directa"8.

El argumento de la causalidad es precisamente el elegido por los autores que últimamente se han pronunciado sobre el punto. Al efecto se dice que "los distintos perjuicios a los afectados por rebote, tuvieron su origen en un contexto de concausas, en que participó tanto el tercero como la víctima principal, proporción que habrá de tenerse en cuenta para responsabilizar al demandado por los hechos que efectivamente cometió"'. Concordamos con este planteamiento, pues, el establecimiento de la culpa concurrente de la víctima supone elevar la conducta de ésta de una mera condición necesaria para la producción del daño, jurídicamente irrelevante, a una concausa del mismo y, desde esta perspectiva, tanto el agente como la víctima son causantes del daño por rebote sufrido por el tercero. Sin embargo, la doctrina nacional no se ha ocupado de precisar detalladamente el argumento, en particular, no se ha logrado establecer la razón que autoriza en este caso a prescindir del hecho de que la víctima directa es un tercero causante del daño y, por tanto, en principio, podría alegarse una aplicación del artículo 2317 CCCh. Sobre este punto volveremos en lo sucesivo.

\section{La oponibilidad de la culpa de la víctima directa a la víctima por rebote} como tendencia en la jurisprudencia de la Corte Suprema.

En la jurisprudencia nacional, al igual que en Derecho extranjero ${ }^{10}$, la

${ }^{6}$ Cfr. Domínguez Águila, El hecho de la víctima, cit. (n. 1), p. 52.

7 Ídem.

${ }^{8}$ Domínguez Águila, Inaplicabilidad, cit. (n. 1), p. 362.

9 Bahamondes y Pizarro, cit. (n. 1), p. 50. En sentido crítico, vid Wegner A., cit. (n. 1), p. 750.

${ }^{10}$ Para un análisis comparado de este asunto vid MAgnus, Ulrich, MarTínCASAls, Miquel, Unification of Tort Law: Contributory negligence (La Haya, Kluwer International, 2003), passim.; ProençA, José Carlos, Brandão, A conduta do lesado como presuposto e criterio de imputação di dano extracontractual (Coimbra, Almedina, 
tendencia ampliamente mayoritaria de los últimos quince años es aceptar la procedencia de la rebaja de la indemnización ${ }^{11}$. Siguiendo principalmente las opiniones de Domínguez y Barros, en numerosas sentencias la Corte Suprema ha aceptado la procedencia de aplicar el artículo $2330 \mathrm{CCCh}$. cuando quien demanda es una víctima por rebote. De esta manera, la revisión de la jurisprudencia de la Corte Suprema da cuenta de una amplia tendencia en el sentido que la culpa de la víctima directa resulta oponible a la víctima por rebote y, por tanto, procede a su respecto la reducción ordenada por el artículo 2330 CCCh. A modo de ejemplo, en tal sentido pueden citarse los siguientes fallos de la Corte Suprema:

a) Fallo de 15 de diciembre de 2009 , a propósito del daño moral demandado por los padres de un joven que falleció en un accidente vehicular, al transitar como acompañante en una motocicleta sin el caso protector exigido por la ley. La Corte Suprema resolvió que "no siendo, entonces, imputable en su integridad a la conducta del demandado la generación del daño, por haber interferido en la cadena causal que condujo a ese resultado un comportamiento falto de prudencia por parte de la víctima, no resulta ajustado a la equidad que aquél haya de asumir el resarcimiento completo del perjuicio que se reclama mediante la presente acción indemnizatoria, correspondiendo que, en atención, a la concurrencia de dicha conducta el monto de la reparación se reduzca, con arreglo a lo dispuesto en el referido artículo 2330 del Código Civil, desde que no se advierte la razón por la cual la aminoración del perjuicio, producida en las circunstancias descritas, tenga lugar cuando el

2003), pp. 698 ss. A nivel legislativo, este punto se encuentra expresamente resuelto en Alemania, cuyo Código Civil, establece expresamente la oponibilidad de la culpa de la víctima directa a la víctima por rebote. Vid BGB, parágrafo 846. Asimismo, ha sido recogido en los Principios Europeos de Responsabilidad Extracontractual (PETL), artículo 8:101. Vid European Group on TorT Law, Principles of European Tort Law. Text and Commentary (Viena, Sprimger, 2005), pp. 130 ss.

${ }^{11}$ Hacemos el corte en los últimos quince años por dos razones, primero, porque constituye el arco de tiempo relevante para el proyecto Fondecyt del cual este trabajo forma parte y, lo más importante, porque la revisión jurisprudencial indica que las últimas sentencias de Corte Suprema que sistemáticamente niegan la procedencia de la reducción a las víctimas por rebote son de fines de los años novena $(v \cdot g r$. Corte Suprema, 11 de agosto de 1998, Rol No 1904-1998). Con posterioridad y sin perjuicio de algunas raras excepciones, el máximo tribunal constantemente ha aceptado la oponibilidad. V. gr. Corte Suprema, 3 de junio de 2002, Rol No 2792-2001; Corte Suprema, 15 de diciembre de 2009, Rol No 3345-2008; Corte Suprema, 7 de junio de 2012, Rol No 8937-2009; Corte Suprema, 23 de julio de 2015, Rol No 22632-2014; Corte Suprema, 10 de diciembre de 2015, Rol No 25380-2014; Corte Suprema, 3 de agosto de 2016, Rol No 20172-2015. Vid también Corte de Apelaciones de Santiago, 22 de agosto de 2006, Rol No 25021-2002; Corte de Apelaciones de Valparaíso, 22 de abril de 2008, Rol No 11549-2007. 
ofendido sobrevive y demanda indemnización por sus lesiones o, cuando, por haber fallecido, impetran lo mismo los herederos, como sus sucesores legales y no se haga extensivo ese efecto mitigante del daño respecto de quienes, como los demandantes de autos, no han alegado tal condición, sino que han accionado en el juicio como victimas mediatas, invocando un daño propio que los afecta en forma refleja o por repercusión" 12 .

b) Fallo de 23 de julio de 2015, a propósito del daño moral demandado por los padres y hermanos de un menor, de quince años, quien falleció a raíz de la caída sufrida en una pelea escolar. La Corte Suprema, luego de haber ampliamente analizado la doctrina favorable a la oponibilidad de la culpa de la víctima directa a los demandantes, acoge el recurso de casación interpuesto el colegio demandado, afirmando: "Que a la luz de lo expuesto en los motivos anteriores, surge evidente que aun cuando se haya establecido que el colegio Junior College S.A. no adoptó las medidas necesarias para evitar las nefastas consecuencias del actuar de su alumno Felipe Camp, es innegable también que a ello se sumó su actuación precipitada, descuidada e imprudente, de lo que cabe colegir que los jueces del fondo infringieron lo previsto en el artículo 2330 del Código Civil, al declarar que no procedía aplicar la reducción a que se refiere ese precepto legal por estimar que los demandantes, al actuar por si mismos y no como herederos de su hijo y hermano, no tomaron parte en los acontecimientos en que falleció Felipe y que éste, además, no se expuso imprudentemente al daño, calificando su accionar como una autodefensa frente al agravio de que su hermano Roberto era victima, sin que fuera previsible suponer que caería de las gradas al ir a increpar al alumno Ignacio Riveros, inobservancia que ha de ser sancionada con la invalidación de lo resuelto, pues la sentencia objeto de alzamiento no puede ser mantenida, si se tiene todavia en cuenta que de ese error ha seguido una decisión necesariamente diversa a la que se habría debido arribar en caso contrario, puesto que de haberse aplicado tal norma como en derecho correspondía habría concluido con el acogimiento de la acción resarcitoria, reduciendo el quantum indemnizatorio conforme lo previsto en dicho precepto, con lo que se satisface el requisito de que los yerros tengan influencia decisiva en lo resuelto"13.

12 Corte Suprema, 15 de diciembre de 2009, Rol No 3345-2008. En términos similares, la Corte de Concepción sostuvo que "la relación que une a la víctima directa con la víctima por repercusión hace posible para ésta alegar su propio daño. Sin esa relación con la víctima no existiría el daño por repercusión. Si la víctima directa incurrió en culpa, parece del todo justo que la indemnización que piden las víctimas indirectas, sea también disminuida por la exposición imprudente al daño que hizo aquélla”. Cfr. Corte de Apelaciones de Concepción, 15 de abril de 2011, Rol No 1495-2010.

${ }^{13}$ Cfr. Corte Suprema, 23 de julio de 2015, Rol No 22632-2014. 
c) Fallo de 24 de noviembre de 2015, a propósito del daño moral demandado por los padres de un conductor quien, conduciendo en estado de ebriedad, realizó una maniobra imprudente que determinó que Carabineros lo confundiera con unos delincuentes, que habían recientemente asaltado un cajero automático, y le disparara ocasionándole la muerte. La Corte de Apelaciones de Chillán niega la procedencia de la reducción fundada en el artículo $2330 \mathrm{CCCh}$, afirmando que la culpa de la víctima directa no se transmitía a los demandantes. La Corte Suprema analiza la doctrina favorable al argumento y acoge el recurso de casación presentado por el Fisco. En la sentencia de reemplazo, la Corte resuelve que "no siendo imputable en su integridad a la conducta del agente del demandado la generación del daño, por haber inferido en la cadena causal que condujo a ese resultado un comportamiento inexplicable y falto de prudencia por parte de la víctima, no resulta ajustado a derecho que aquél haya de asumir el resarcimiento completo del perjuicio que se reclama mediante la presente acción indemnizatoria" 14.

Con todo, no puede desconocerse la existencia de una opinión jurisprudencial minoritaria, que niega la oponibilidad de la culpa de la víctima directa a la víctima por rebote. Este es el caso de la reciente sentencia de 28 de septiembre de 2016, en que, a propósito de un accidente del trabajo con resultado de muerte, se negó la rebaja de la indemnización a las víctimas que habían demando iure propio, argumentando que se trataba de un daño diverso y que estas víctimas no se habían expuesto a sufrirlo ${ }^{15}$. Así las cosas, a pesar de la tendencia jurisprudencial mayoritaria y de los esfuerzos doctrinarios, todavía es posible encontrar opiniones contrarias a la oponibilidad de la culpa de la víctima directa a las víctimas por rebote. En consecuencia, es necesario considerar con mayor precisión los fundamentos y el funcionamiento práctico de la institución, con el fin de lograr claridad sobre el argumento. A ello nos abocaremos en el punto siguiente.

\section{La culpa de la víctima directa como concausa del daño por rebote y el problema de la solidaridad.}

Como puede apreciarse, los fragmentos de sentencia transcritos en el punto anterior aluden a la causalidad como fundamento concluyente para oponer la culpa concurrente de la víctima directa a la víctima por rebote. La aplicación del artículo 2330 al caso en análisis sería, por tanto, la consecuencia del principio de reparación integral del daño mirado desde

${ }^{14}$ Cfr. Corte Suprema, 24 de noviembre de 2015, Rol No 6887-2015, sentencia de reemplazo.

15 Vid Corte Suprema, 28 de septiembre de 2016, Rol No 7237-2915, dictada en fallo dividido, con dos votos en contra. Asimismo, es del caso reportar la sentencia de Corte de Apelaciones de Rancagua, 9 de junio de 2016, Rol No 2040-2014. 
la perspectiva del agente, esto es, su derecho a no indemnizar más que el daño jurídicamente imputable a su conducta. La culpa de la víctima directa aparece como una concausa a la cual debe imputarse parcialmente el daño sufrido por la víctima por rebote y, por consiguiente, el demandado no debe soportar íntegramente la indemnización demandada.

Tal construcción, desde luego útil para explicar la injusticia de atribuir la reparación integral del daño al demandado, pone a la víctima directa como coautora del propio daño y, por tanto, del daño por rebote. En otras palabras, ello significa que, jurídicamente, el daño por rebote es producto del actuar de dos sujetos: el agente (demandado) y la víctima directa, sin que pueda imputarse íntegramente a la conducta del primero. Así las cosas, esta forma de abordar el problema se encuentra de frente con la solidaridad que el artículo 2317 CCCh impone a los coautores de un mismo daño ${ }^{16}$. En efecto, si ambos sujetos (agente y víctima directa) son coautores del daño por rebote, podría sostenerse que ambos son jurídica y solidariamente responsables frente a la víctima indirecta. Así las cosas, la construcción fundada en la causalidad es útil para explicar la contribución a la deuda (el demandado es responsable sólo parcialmente del daño causado), pero no la obligación a la deuda (en principio, la víctima tiene derecho a dirigirse contra cualquiera de los responsables por el total). En resumen, dado que ambos son coautores, el tercero demandado y la víctima directa serían solidariamente responsables del daño por rebote $\mathrm{y}$, por tanto, la víctima indirecta podría obtener la reparación integral del daño del demandado, quien, a su vez, podría dirigirse en contra de la víctima directa o sus herederos.

Una forma de salir de esa disyuntiva es enfrentar el problema desde el Derecho sucesorio, considerando que si las de víctimas por rebote son, a su vez, herederos de la víctima directa, no es procedente reclamen una indemnización integral del daño, pues, por vía de la acción de repetición, deberían restituir ${ }^{17}$. Operaría así una verdadera compensación de deudas entre el tercero demandado y el demandante. Con todo, si bien esta idea resulta válida cuando se trata de víctimas por rebote que, a su vez, sean herederas de la víctima directa ${ }^{18}$, lo cierto es que desde hace ya varios años la indemnización del daño por rebote se ha visto ostensiblemente ampliada $^{19}$, en dos sentidos: por un lado, se concede el daño por rebote en

16 Díez Schwerter, cit. (n. 1), p. 237 ss.

17 Domínguez Águila, El hecho de la víctima, cit. (n. 1), p. 50.

${ }^{18}$ Esto sin considerar el problema de la repartición entre los distintos herederos.

19 Si bien una parte de la doctrina tiende a identificar a las víctimas por rebote con los herederos y limitar su presencia a los casos de daños derivados de la muerte, lo cierto es que la doctrina mayoritaria no lo ve de esta manera y, sobre todo, no 
caso de lesiones corporale $\mathrm{s}^{20} \mathrm{e}$ incluso por daño a la honra ${ }^{21}$, con lo cual no puede hablarse de herederos; por otro lado, se ha ampliado el círculo de los legitimados para demandar el daño por rebote, incluyendo a personas que no tienen la calidad de herederos del causante, por ejemplo, al conviviente de hecho ${ }^{22}$. Así las cosas, cabe preguntarse si podrían las víctimas por rebote invocar la solidaridad del artículo 2317 y, en consecuencia, obtener la indemnización integral del daño sufrido del tercero agente y que luego éste se entienda con la víctima directa o sus herederos.

Cabe señalar desde ya que estimamos que la respuesta a tal pregunta es negativa. No parece posible que en este caso opere la regla de la solidaridad impuesta por el artículo 2317 CCCh. Para explicar esta idea, es necesario recordar los objetivos perseguidos por cada una de las normas relevantes en este caso, los artículos 2330 y 2317 . El primero impone al agente una responsabilidad parcial fundada en la autorresponsabilidad de la víctima, a quien debe atribuirse parte del daño sufrido; su objetivo es cumplir con la máxima según la cual el agente no debe sino el daño que le resulta jurídicamente imputable. El segundo, en cambio, impone una indemnización integral fundada en la pluralidad de causantes; su objetivo es proteger a la víctima asegurándole la indemnización mediante la constitución de una garantía legal. En efecto, si bien a primera vista la norma del artículo 2317 aparece como una consecuencia de la doctrina de la equivalencia de

es eso lo que ocurre en la jurisprudencia. Además de los fallos citados en las notas siguientes, vid DíEz SCHWERTER, José Luis, Victimas indirectas y por repercusión en la responsabilidad civil derivada de accidentes del trabajo o enfermedades profesionales en nuestra jurisprudencia reciente: del problema de la competencia a las distorsiones sustanciales, en Revista de Derecho - Universidad de Concepción 214 (2003), pp. 65 ss.; Elorriaga de Bonis, Fabían. Novedades judiciales en torno al daño moral por repercusión, en Corral Talciani, Hernán y Rodríguez Pinto, María Sara (coordinadores), Estudios de derecho civil II (Santiago, AbeledoPerrot - LegalPublishing, 2007), pp. 297 ss.; KunKar ONETO, Andrés, ¿Es el estatuto de la responsabilidad extracontractual aplicable a las victimas por repercusión o rebote?, en ELORRIAGA DE BONIS, Fabián (coordinador), Estudios de derecho civil VII (Santiago, AbeledoPerrot - Thomson Reuters, 2012), p. 705 ss.

${ }^{20}$ V. gr. Corte Suprema, 5 de marzo de 2007, Rol No 603-2006.

${ }^{21}$ V. gr. Corte Suprema, 20 de agosto de 2015, Rol No 22835-2014.

${ }^{22}$ Piénsese en el siguiente caso, más frecuente de lo que se quisiera, una pareja de convivientes de hecho, en que el hombre, sostenedor del hogar común, fallece a consecuencia de un accidente del trabajo, donde suele invocarse la culpa de la víctima. Los hijos del fallecido no reconocen ningún derecho a la mujer sobre los bienes del mismo y, además, a su respecto se aplica la culpa concurrente del mismo. En este caso, no parece tan descabellado aplicar la responsabilidad solidaria del empleador y que luego se dirija en contra de los herederos. 
las condiciones ${ }^{23}$, entre los autores nacionales existe consenso en torno a que ella se justifica en la protección de la víctima, para que obtenga más fácilmente la reparación del daño sufrido ${ }^{24}$. Sin embargo, en la contribución a la deuda, cada agente responde según los criterios propios de repartición de responsabilidades entre pluralidad de responsables, que en sustancia corresponden a los mismos empleados para distribuir el daño entre agente y víctima, para el caso de culpa concurrente de esta última ${ }^{25}$.

En síntesis, al imponer la solidaridad como garantía de cumplimiento de la obligación indemnizatoria, el artículo 2317 constituye una excepción a la regla general del carácter simplemente conjunto o conmutativo de las obligaciones $y$, en consecuencia, debe interpretarse restrictivamente. A este razonamiento, debe agregarse la circunstancia, ya puesta en evidencia por Domínguez Águila, de la interdependencia de las acciones de daños

${ }^{23}$ Según enseña la doctrina que se ha ocupado del argumento, dos teorías explican la imposición de solidaridad a los coautores de un daño: (i) la teoría clásica, según la cual cada coautor es considerado autor de la integridad del mismo, en virtud del principio de equivalencia de las condiciones; y (ii) la teoría moderna, que la considera una garantía para la víctima. Vid CHABAs, François, L’influence de la pluralitè de causes sur le droit a réparation (París, L.G.D.J., 1967, pp. 9 ss.); Di MAJO, Adolfo, Obligazione solidali (e indivisibili), en Enciclopedia del Diritto, vol. XXIX (Milán, Giuffrè, 1979), pp. 321 ss.; Franzoni, Massimo, Fatti illeciti. Commentario del Codice Civile Scialoja-Branca. Obligazioni art. 2043-2059 (Bolonia, Zanichelli, 1993), pp. 713 ss.; VIOLANTE, Umberto, La responsabilità parziaria (Napoli, Edizioni Scientifiche Italiane, 2004), pp. 93 ss.; GNANI, Alessandro, La responsabilità solidale. Art. 2055 (Milán, Giuffrè, 2005), pp. 11 ss. La consecuencia práctica de una y otra alternativa, es que la primera no concede acción de reembolso a quien resulte obligado al pago, pues se lo considera autor del total del daño, mientras que la segunda sí otorga dicha acción, estableciendo mecanismos de reembolso. Es precisamente por esta última razón que en la actualidad se ha desechado la primera doctrina y se acoge la segunda. Así ha sido expresamente reconocido en los PETL, artículos 9:101 y 9:102. Vid European Group on Tort Law, cit., (n. 9), p. 142 ss.

${ }^{24}$ Vid Domínguez Águila, Ramón, Aspectos de la relación de causalidad en la responsabilidad civil con especial referencia al Derecho chileno, en Revista de Derecho Universidad de Concepción, 209 (2001), pp. 20 ss.; PiZArro Wilson, Carlos, Mal praxis en el equipo médico, en Revista Médica de Chile, 139 (2011), p. 670. A la misma conclusión han llegado la doctrina y jurisprudencia italianas, a propósito del artículo 2055 CCIt., que contiene una norma similar al artículo 2317 chileno. Vid GNANI, cit. (n. 23), pp. 11 ss.

${ }^{25}$ Domínguez Águila, Aspectos de la relación de causalidad, cit. (n. 1), pp. 21-22; Barros Bourie, cit., (n. 1), p. 424. La correspondencia entre ambas series de criterios fue expresamente sostenida por el legislador italiano de 1942, en los artículos 1227 y 2055 del Codice Civile, sobre culpa concurrente y solidaridad entre coautores, respectivamente. Cuáles son en concreto estos criterios es una cuestión que escapa ampliamente a este trabajo. $\mathrm{Al}$ respecto, vid GNANI, cit., (n. 22), pp. 189 ss. 
de la víctima directa y de la víctima por rebote. Esta interdependencia determina que la víctima por rebote no pueda aparecer frente al tercero como un sujeto totalmente ajeno a la víctima directa y, en consecuencia, pretender que aquel le indemnice integralmente el daño sufrido. Esta situación es indudable cuando la víctima por rebote reviste, además, la calidad de heredero de la víctima directa; empero, estimamos que ella se aplica respecto de todas las víctimas indirectas, toda vez que todas ellas fundan su acción de indemnización en el estrecho vínculo que les une con la víctima directa ${ }^{26}$.

Finalmente, como último argumento, a nuestro juicio decisivo, cabe considerar que el artículo 2317 impone la solidaridad cuando se trate de delito o cuasidelito, es decir, cuando se trate de indemnizar el daño causado a un tercero como resultado de la violación de un deber jurídico de conducta. Aceptado este antecedente, hay que recordar que técnicamente la víctima no está gravada con un deber, sino con una carga de diligencia en la conservación y salvaguarda de los propios intereses ${ }^{27}$. Salvo hipótesis particulares ${ }^{28}$, las personas no tenemos un deber de cuidarnos en beneficio de los terceros, de ahí que, por regla general, tampoco estemos obligadas a indemnizar a los terceros que resulten perjudicados como consecuencia de nuestras lesiones. En efecto, si una persona intenta el suicidio, no pueden sus familiares y amigos demandarla para que les indemnice el daño moral sufrido, pues no han sido víctimas de la violación de un deber $^{29}$, sino de

${ }^{26}$ Un problema diferente al abordado en esta sede es aquel en que, a raíz del accidente a cuya producción ha contribuido la culpa de la víctima, resultan lesionados terceros, en calidad de víctimas directas o por rebote. Este es, por ejemplo, el caso en que la contribución del conductor determina un accidente en que resulta muerto o gravemente lesionado el copiloto. Aquí, pareciera que estamos precisamente frente al caso del artículo 2317, pues ambos sujetos, conductor y tercero, son causantes del daño sufrido por el copiloto y sus deudos. Con todo, no hemos encontrado fallos en que se discuta este punto, en consecuencia, las decisiones sobre este tipo de casos no han ido en esa línea. Vid Corte Suprema, 3 de agosto de 2016, Rol No 20172-2015.

${ }^{27}$ Sobre la configuración de esta carga, desde el Derecho romano hasta el Código Civil chileno, vid SAN MarTín NeIRA, Lilian C., La carga del perjudicado de evitar o mitigar el daño (Bogotá, Universidad Externado, 2012), passim.

${ }^{28}$ En algunos casos las personas sí tienen obligación de cuidarse, por ejemplo, un actor que se compromete a no realizar actividades que puedan perjudicar su integridad física mientras dure el rodaje de un film, o bien las que pesan sobre ciertas autoridades mientras dure su mandato, pero esto supone la existencia de una fuente precisa de la obligación.

${ }^{29}$ Un razonamiento análogo se encuentra en la doctrina italiana, que excluye la posibilidad de aplicar la solidaridad fundado en que "il fatto colposo della vittima non costituisce violazione di un diritto dei congiunti". Cfr. BIANCA, C. Massimo, Diritto Civile 5. La responsabilità (Milán, Giuffrè, 2004), p. 141, n. 86. 
la inobservancia de una carga, que se caracteriza precisamente por la inexigibilidad de la conducta y la improcedencia de resarcimiento para el caso de inobservancia ${ }^{30}$. En síntesis, por regla general, la víctima tiene sólo una carga de autocuidado y el interés de los terceros en no verse perjudicados no es más que el reflejo de esta carga, de ahí que carezcan de derecho para ser indemnizados por el daño que sufran ${ }^{31}$.

La conjunción de todos esos aspectos determina que quede excluida la posibilidad de aplicar el artículo 2317 CCCh y, por tanto, el agente no debe indemnizar sino la parte de daño que le resulta jurídicamente imputable, sin que haya lugar a indemnización por el daño por rebote causado por la víctima directa, pues, dado que carece de acción para dirigirse contra la víctima directa, la víctima por rebote carece de legitimidad para reclamar una indemnización por esta parte.

${ }^{30}$ En el género de los deberes jurídicos es posible distinguir entre deber (en sentido restringido), obligación y carga. Dejando de la lado la obligación, que se caracteriza por la existencia prestación y sujetos determinados, la distinción entre deber y carga pasa por establecer el beneficiario de la norma y la posibilidad de que los terceros exijan la observancia de la conducta prescrita. En particular, la carga se caracteriza porque el beneficiario es el mismo sujeto gravado con la conducta y los terceros no pueden exigir su observancia, ya sea en naturaleza o por equivalencia; es decir, en la medida que los efectos de la inobservancia de la norma se radican en el sujeto gravado con la misma (autorresponsabilidad), la carga no da lugar a ejecución forzada, ni tampoco a responsabilidad civil. Para mayores profundizaciones sobre la distinción entre deber y carga, vid Cabanilla Sánchez, Antonio, Las cargas del acreedor en el derecho civil y en el mercantil (Madrid, Montecorvo, 1988), p. 50 ss.; San Martín Neira, La carga, cit. (n. 23), pp. 68 ss.

${ }^{31}$ El que los terceros resulten beneficiados con la observancia de la conducta (en este caso, queden indemnes) no es de suyo incompatible con la noción de carga, lo relevante es la inexigibilidad de la misma. En este mismo sentido se pronuncia BETTI quien señala: "Certamente il comportamento ch'è oggetto di onere può essere guardato tanto dal punto di vista di colui cui l'onere è imposto, quanto dal punto di vista della controparte o del terzo che ne risulta avvantaggiato; e da quest'ultimo angolo visuale appare protetto con esso anche l'interesse altrui. Ma la questione non si risolve con questo spostamento di visuale (...) per la decisiva ragione che la controparte o il terzo non può esigere l'osservanza dell'onere contro l'inerzia dell'onerato che non si curi del risultato utile del proprio comportamento; laddove, quando l'onerato aspiri a tal risultato e si comporti in conseguenza, il vantaggio della controparte e del terzo non è che il rifleso meramente eventuale del risultato stesso". Cfr. BETTI, Emilio, Teoria generale del negozio giuridico, (reimpresión corregida de la 2a ed., al cuidado de Giuliano Crifó, Napoli, Edizioni Scientifiche Italiane, 2002), p. 112. 


\section{LA CULPA DEL GUARDIÁN COMO CAUSAL DE DISMINUCIÓN} DEL DAÑO PROPIO ¿Y TAMBIÉN DE LA VÍCTIMA DIRECTA?

\section{La culpa del guardián como elemento reductor del daño propio.}

Las personas que carecen de discernimiento para autogobernarse, esto es, los incapaces, quedan al cuidado de otra persona, quien asume el deber de velar por ellas. Según se ha resuelto, este deber alcanza la obligación de impedir que el incapaz se autolesione, de manera que, si por su falta de vigilancia el incapaz resulta lesionado, puede demandarse la responsabilidad del cuidador. Tal responsabilidad puede ser invocada por el mismo incapaz o bien por eventuales víctimas por rebote, por ejemplo, en caso de que un enfermo mental que cometa suicidio, a raíz de la mala praxis del instituto psiquiátrico o centro hospitalario en que estaba internado ${ }^{32}$.

En esta sede, cobra especial relevancia la posibilidad de que las víctimas por rebote coincidan con las personas responsables del cuidado del incapaz y que su negligencia haya contribuido a la producción del daño sufrido por la víctima directa incapaz. Un famoso caso de la jurisprudencia española es ilustrativo de esta hipótesis, se trataba de unos padres que enviaron a su hija de diez años a un campamento de verano, sin advertir a los organizadores que la niña padecía una enfermedad renal crónica y que la actividad física le estaba desaconsejada por sus médicos. Una vez en el campamento, la niña realiza gran esfuerzo físico y fallece. El tribunal consideró que los organizadores del campamento habían incurrido en negligencia y, por tanto, eran responsables de la muerte; sin embargo, estimó también que los principales causantes del fallecimiento de la niña habían sido sus padres, por no advertir de su enfermedad y cuidados necesarios. En consecuencia, aplicó la culpa concurrente de la víctima y redujo la indemnización en un noventa por ciento ${ }^{33}$.

Estimamos que no existe inconveniente para un razonamiento semejante se aplique en la jurisprudencia nacional, pues la normativa aplicable es del todo análoga ${ }^{34}$. De esta manera, si el encargado del cuidado de la víctima

32 V. gr., vid Corte Suprema, 25 de julio de 2016, Rol No 1511-2016. Si bien la sentencia, en su voto de mayoría, finalmente no condena al hospital demandado, sí reconoce que esta es una posibilidad, descartando la responsabilidad sobre la base de que el hospital no habría incurrido en falta de servicio. Distinta es la opinión del voto de minoría, que sí dio por configurada la falta de servicio.

33 Sentencia del Tribunal Supremo Español, STS de 23 de febrero de 1996, citada en Roca, Encarna, Derecho de daños, $4^{\mathrm{a}}$ ed. Valencia, Tirant lo Blanch, 2003, pp. 170-171.

${ }^{34}$ En la jurisprudencia nacional encontramos casos en que se ha efectuado este razonamiento. Así, en el caso en que los padres dejan a un infante sin vigilancia en 
ha actuado negligentemente, puede aplicarse a su respecto la reducción de su daño moral y patrimonial, lo que constituye una consecuencia lógica del principio de resarcimiento integral del daño $0^{35}$.

\section{Posición de las demás víctimas por rebote frente a la culpa del guardián:} ¿tiene derecho el demandado a invocar la solidaridad del artículo 2317?

Establecido que la víctima por rebote que sea, a su vez, custodio o guardián del incapaz puede sufrir una reducción de su indemnización fundada en la culpa propia, resulta legítimo preguntarse qué pasa respecto de las demás víctimas por rebote, por ejemplo, el padre que no vivía con el menor que se autolesiona a consecuencia de la negligencia de la madre. En este caso, surge nuevamente el problema de la solidaridad antes visto. Ciertamente, la víctima por rebote que no ha contribuido a la producción del daño principal no tiene por qué sufrir la reducción y, además, a su respecto debería aplicarse el artículo 2317, es decir, tendrá derecho a demandar indemnización integral del tercero agente. El corolario lógico de esta afirmación sería que el agente, relativamente a la indemnización que pague a la víctima aquí aludida, tendrá derecho al reembolso en contra del cuidador de la víctima directa. Sin embargo, no ha sido esta la solución sostenida por la jurisprudencia, cuando menos en el único que conocemos en que se discutió este asunto.

En efecto, la Corte Suprema tuvo ocasión de pronunciarse sobre lo que venimos diciendo, a propósito del caso de un menor que vivía con sus abuelos, quienes lo dejaron ir a jugar a una estación de trenes abandonada donde había varios elementos peligrosos (sin analizar la culpa del menor ${ }^{36}$ ). La Corte de Punta Arenas decidió que sólo daría resarcimiento por el daño moral a la madre y a la hermana, y se lo negó a los abuelos fundándose en que éstos cometieron un descuido al permitir que el menor fuera a jugar a un lugar conocidamente peligroso ${ }^{37}$. El demandado recurrió de casación fundándose en que la Sentencia reconocía que el verdadero causante de la muerte del menor era el abuelo o que, a lo menos, éste era coautor del daño y, por ende, procedía la aplicación del artículo 2317. Sin embargo, el máximo tribunal rechazó el recurso, acudiendo a una aplicación extrema

terrenos donde se efectuaba una excavación. Vid Corte de Apelaciones de Concepción, 23 de abril de 1985, RDJ, t. LXXXIII, sec. 1ª, p. 96.

35 En sentido similar, Wegner A., cit. (n. 1), p. 752.

${ }^{36}$ No sabemos si fue discutido en primera instancia, pero ni en segunda instancia, ni en la casación se analizó la actitud imprudente del menor.

37 Corte de Apelaciones de Punta Arenas, 7 de junio de 2011, Rol No 97602004 . 
de la teoría de la equivalencia de las condiciones y sin pronunciarse sobre el derecho a reembolso cuya declaración se solicitón ${ }^{38}$.

Una situación semejante, aunque en la causa no se discutió la aplicación del artículo 2317, se produjo en el fallo dictado a propósito de un menor de seis años que resultó gravemente lesionado luego de introducirse a una central termoeléctrica. En el caso, la Corte Suprema, por un lado, admite la culpa concurrente de los padres, por no haber vigilado adecuadamente al menor, pero la excluye expresamente respecto de los hermanos, señalando que "los hermanos del accidentado, también menores de edad e incapaces para la ley no pueden ser legitimados pasivos de esta reducción y porque, además, no hay ningún antecedente que demuestre alguna exposición imprudente del lamentable suceso" ${ }^{\prime 9}$. Como se advierte, la Corte excluye la reducción de la indemnización a los hermanos de la víctima sobre la base de un argumento jurídico: la imposibilidad de configurar respecto de estos una culpa concurrente. Este razonamiento resulta contradictorio, cuando se considera, por un lado, que la aplicación del artículo 2330 a las víctimas por rebote no exige que estas se hayan personalmente expuesto al daño y, por otro lado, que en el caso no se dio por establecida la culpa concurrente de la víctima directa, la que obtuvo la indemnización integral del daño padecido. Para ser justos, es necesario señalar que en este caso la Corte mitiga los efectos de la contradicción expuesta señalando que "estos hermanos igualmente recibirán una cantidad sustancialmente menor, toda vez, que por su corta edad no es posible asimilar el dolor sufrido por éstos al mismo que hayan padecido la víctima y sus padres" ${ }^{40}$. Con todo, esta solución no elimina el problema de fondo, esto es, que, según lo expresamente resuelto por el máximo tribunal, el daño sufrido por los hermanos de la víctima emana tanto de la negligencia de la termoeléctrica, como de la de sus padres $^{41}$; sin embargo, obtienen la indemnización integral del daño de parte de la primera, sin posibilidad de repetir contra los segundos. Estimamos que esta situación lesiona el principio de reparación integral del daño en

${ }^{38}$ En palabras de la Corte, "basta que el daño tenga al hecho culpable por condición necesaria (aunque sea una entre otras) para que haya lugar a la responsabilidad". Cfr. Corte Suprema, 8 de enero de 2013, Rol No 10830-2011.

${ }^{39}$ Corte Suprema, 5 de marzo de 2007, Rol No 603-2006, sentencia de reemplazo.

40 Ídem.

${ }^{41} \mathrm{Al}$ acoger la excepción del artículo 2330 la Corte señala: "Que, en todo caso, también parece atendible la excepción de reducción que opuso la demandada, la que en el presente caso deberá operar sólo respecto de los padres, puesto que en el accidente que sufrió su hijo no adoptaron todas las medidas de cuidado que por la corta edad de la víctima les correspondía" [énfasis añadido]. Ídem. 
su faz pasiva: el agente no debe indemnizar más que el daño que le resulte jurídicamente imputable.

En efecto, no debe perderse de vista que el principio de resarcimiento integral del daño puede ser mirado desde el lado de la víctima (faz activa), así como del lado del agente (faz pasiva). Para la víctima, este principio tiene dos vertientes: establece el derecho a la completa reparación del daño y señala que ésta no puede constituir una fuente de enriquecimiento. Para el agente, se traduce en que será obligado a indemnizar sólo los daños que le sean jurídicamente imputables, de ahí que para él sea relevante el hecho de que en el juicio se determine la existencia de otro sujeto jurídicamente causante del daño reclamado por la víctima, pues éste, en virtud de las reglas que rigen al principio de responsabilidad, también debe contribuir a la reparación del daño. En consecuencia, dogmáticamente no existe inconveniente alguno para que el demandado invoque la regla del artículo 2317 y exija al guardián que contribuya a indemnizar a las demás víctimas por rebote.

Admitida la relevancia de la culpa del guardián para la extensión de la indemnización debida por el demandado, es necesario considerar la aplicación práctica de esta idea y el momento en que se haría valer. En los casos en que el guardián tenga derecho a una indemnización, aunque disminuida por su contribución al daño, la solución debiera ser rebajar también de esta indemnización la cuota que le corresponde en la indemnización demandada por las demás víctimas por rebote, quienes tienen como causantes del daño sufrido tanto al demandado como al guardián. En efecto, sería un contrasentido condenar al demandado a pagar al guardián una suma que luego éste debería restituirle, con todas las dificultades que ello entraña. Lo más sensato sería que el juez determine la cuantía del daño sufrido por él y luego le aplique una doble rebaja: la correspondiente a la contribución en su propio daño y la correspondiente a su contribución en el daño de las demás víctimas por rebote, a cuyo favor se ha sentenciado una indemnización. Por lo anterior, sin perjuicio de que no se encuentre expresamente regulado y que en estricto rigor no sean aplicables las reglas de la compensación de deudas, estimamos que es posible solicitar al juez que realice estos cálculos y ajuste desde luego la indemnización del guardián a lo que estrictamente le corresponde, sin tener que recurrir a la repetición. Consideramos que, en virtud de las normas procesales que facultan al juez para fallar con fundamento en la equidad ${ }^{42}$, unidas al principio de

${ }^{42}$ En las normas procesales está expresamente permitido que el juez invoque principios de equidad para fundamentar sus decisiones (art. 170 No 5 C.P.C.), los cuales han sido ampliamente utilizados por la jurisprudencia para fundamentar el 
resarcimiento integral mirado desde la perspectiva del agente ${ }^{43}$, el juez tiene facultades para acceder a esta petición, aunque no podría hacerlo de oficio.

Más complicado es el panorama en los casos en que se niega la indemnización al guardián y se concede solo las demás víctimas por rebote ${ }^{44}$. En este tipo de casos, atendido el panorama legislativo, el juez debería condenar al demandado al pago íntegro de la indemnización, concediéndole la posibilidad de repetir en contra del guardián. Con todo, esta solución resulta criticable, no solo porque es posible que el demandado finalmente no obtenga ninguna restitución, sino porque, en la mayoría de los casos, se tratará de un mismo núcleo familiar y el efecto de recibir y repetir será exactamente el mismo. En otro orden de ideas, atendido que el guardián no ha sido demandado (a menos que se trate de una demanda reconvencional) no es claro que pueda ser legitimado pasivo de una acción dirigida a obtener la restitución de la suma pagada en su lugar, máxime cuando, muy probablemente, ya habrán transcurrido los cuatro años de prescripción de la acción de responsabilidad extracontractual. Para resolver esta cuestión, sería necesario analizar con profundidad la aplicación práctica del artículo 2317, en especial, sería necesario establecer las condiciones de procedencia de la acción de repetición a que da lugar, aspectos que escapan con creces los objetivos de este trabajo ${ }^{45}$.

\section{La posibilidad de traspasar la culpa del guardián a las víctimas inca-} paces de culpa propia.

No obstante que un sector de la doctrina nacional se inclina abiertamente por la posibilidad de aplicar la idea de culpa concurrente de la víctima a las víctimas incapaces ${ }^{46}$, el análisis jurisprudencial realizado en la preparación de este artículo reveló que tal idea no ha sido acogida por

quantum indemnizatorio; por tanto, parecen perfectamente aplicables en este contexto.

${ }^{43}$ El agente no debe soportar un costo mayor al daño que jurídicamente le resulte imputable y, si tuviera que pagar indemnización integral a las demás víctimas indirectas, a cuyo daño ha contribuido el guardián, sin rebajar esa contribución de la suma debida a éste, se le estaría imponiendo una indemnización por sobre ese límite.

${ }^{44}$ Vid Corte de Apelaciones de Punta Arenas, 7 de junio de 2011, Rol No 97602004.

${ }^{45}$ Lamentablemente, la aplicación práctica del artículo 2317 ha sido dejada de lado tanto por los estudiosos de las obligaciones solidarias, como por los estudiosos de la responsabilidad civil, con lo cual no se cuenta con estudios doctrinarios que permitan fundar, ni siquiera someramente, algunas conclusiones en la materia. Esperamos que en el futuro cercano este panorama cambie.

${ }^{46}$ Por todos, vid San Martín Neira, Lilian C. La culpa de la víctima en la estructura de la responsabilidad civil, en Departamento de Derecho Privado Uni- 
la jurisprudencia nacional, la cual continúa a sostener que la aplicación del artículo 2330 exige que la víctima sea capaz de responder civilmente ${ }^{47}$. Aunque no se diga expresamente, este planteamiento jurisprudencial es el corolario de dos razonamientos copulativos: (i) que la noción de culpa seguida por el ordenamiento jurídico nacional incluye la idea de imputabilidad ${ }^{48} \mathrm{y}$, (ii) que sólo en virtud de la culpa es posible considerar la intervención causal de la víctima en la producción del propio daño, la cual deja de ser una condición jurídicamente irrelevante para transformarse en concausa (jurídica) del mismo ${ }^{49}$.

Sin perjuicio de que la extensión de este artículo impide detenerse sobre el punto, es oportuno señalar que, en nuestro parecer, el razonamiento jurisprudencial expuesto encuentra su justificación en la estructura de la responsabilidad civil plasmada en el Código Civil y en el hecho de que, de no ser así, a las víctimas se les impondría un estándar de conducta más elevado en la conservación de los intereses propios que en la conservación de los intereses ajenos. En efecto, el origen de la noción objetiva de culpa tiene su origen en Francia ${ }^{50}$, donde no hay una norma equivalente al artí-

VERSIDAD DE CONCEPCIÓN (editor), Estudios de derecho civil XI (Santiago, Thomson Reuters, 2016), pp. 927 ss.

47 Vid Corte Suprema, 9 de enero de 1996, consultado en: Microjuris, Identificador MJCH_MJJ115; Corte de Apelaciones de Santiago, 11 de septiembre de 2014, Rol No 1651-2014; Corte Suprema, 10 de junio de 2013, Rol No 9554-2012; Corte Suprema, 25 de septiembre de 2012, Rol No 9942-2010.

${ }^{48} \mathrm{La}$ existencia de dos nociones de culpa, una objetiva, que excluye la imputabilidad, y otra subjetiva, que la incluye, ha dado origen a numerosos estudios y no puede ser ni siquiera brevemente abordada aquí, con lo cual la damos como un presupuesto de la investigación.

${ }_{49}$ En efecto, como ha puesto en evidencia Domínguez Águila, la víctima es siempre una condición necesaria del daño, pues sin su presencia el daño no hubiera tenido lugar (Domínguez ÁGuila, El hecho de la víctima, cit. (n. 1), p. 30). Así, para que haya un atropello son necesarios un automóvil y un peatón. En consecuencia, el problema de la culpa concurrente de la víctima se refiere a los casos en que la conducta de ésta adquiere relevancia causal desde el punto de vista jurídico: el peatón ha realizado una conducta jurídicamente relevante. En este sentido se ha dicho que lo que permite asignar relevancia causal a la conducta de la víctima es precisamente su culpa: el peatón atravesó la calle a mitad de cuadra. Todo ello en consideración a la circunstancia que, en un sistema de responsabilidad subjetiva, existe una intrínseca relación entre las nociones de culpa y causalidad. Sobre el particular vid SAN MARTín NeIRA, La culpa, cit. (n. 46), pp. 927 ss.

${ }^{50}$ Por todos, vid Mazeud, Henri, Mazeud, Léon, Tunc, André, Tratado teórico y práctico de la responsabilidad civil, delictual y contractual (Traducc. Luis Alcalá Zamora y Castillo, Buenos Aires, Ediciones Jurídicas Europa-América, 1962), pp. 7 ss.; Fernández Cruz, Gastón, De la culpa ética a la responsabilidad subjetiva: ¿el mito de Sisifo? (panorámica del concepto y del rol de la culpa en el derecho continental y 
culo 2319 del Código Civil chileno, en consecuencia, la noción objetiva produjo una ostensible extensión de la responsabilidad civil a personas que no estaban previamente gravadas con ella, quedando mayormente protegidas las víctimas. En Chile, en cambio, dada la existencia del artículo 2319, la aceptación de una noción objetiva de culpa produciría exactamente el efecto contrario ${ }^{51}$, esto es, un estrechamiento del campo de aplicación de la responsabilidad, pues, al independizarse de la culpa, la capacidad pasaría a exigirse también a los casos de responsabilidad objetiva, en que la culpa no es relevante $y$, consecuentemente, las víctimas verían reducidas sus posibilidades de obtener una indemnización ${ }^{52}$. A su vez, si la disminución del resarcimiento por concurrencia de culpa de las víctimas incapaces de responder frente a terceros implicaría que las víctimas tendrían un estándar de conducta más exigente en la protección de los propios intereses, que en la protección de los intereses ajenos, lo que resulta contradictorio con la idea de carga que regula este tipo de conductas. Cabe señalar que esta reflexión ha llevado a que en algunos ordenamientos rija la regla exactamente contraria, esto es, que el estándar de diligencia consigo mismo sea inferior al estándar de diligencia con los demás ${ }^{53}$, lo cual explica que los

en el Código Civil peruano), en Revista Themis, 50, (2005), pp. 237 ss.; VInEY, Geneviève, Tratado de derecho civil. Introducción a la responsabilidad (Traducc. Fernando Montoy Mateus, Bogotá, Editorial Universidad Externado de Colombia, 2007), pp. 115-116. En Chile, un temprano y muy buen resumen de las diversas opiniones de los autores franceses en este sentido, puede verse en Escribar Mandiola, Héctor, Responsabilidad civil sin culpa, en Revista de Derecho y Jurisprudencia, 20, (1923), pp. 17 ss. Como trabajo más reciente, debe mencionarse Domínguez Águila, Ramón, La culpa en el derecho civil chileno. Aspectos generales, en Revista Anales Derecho UC, 3, (2008), pp. 107 ss.

${ }^{51}$ Sobre las incongruencias a que puede llevar la adopción de la noción de culpa objetiva en países regidos por el Código de Bello, Mantilla Espinosa, Fabricio, TerNERA BARRIOS, Francisco, La noción de culpa en la responsabilidad extracontractual, en Actualidad Jurídica, 11, (2005), pp. 213-230, especialmente pp. 222 ss.

52 Podría perfectamente ocurrir que una persona, desarrollando lícitamente una actividad que genera responsabilidad objetiva (manejar residuos peligrosos en los términos de la reciente Ley No 20.920, por ejemplo), sufra una privación de razón que le induzca a causar daño. La pregunta es, ¿se aplica o no el artículo 2319? Si entendemos que la imputabilidad es un presupuesto de la responsabilidad civil en general, la respuesta es sí y, por tanto, la persona no responde. Si entendemos que es un componente o presupuesto de la culpa, la respuesta es no y, por tanto, la persona sí responde.

53 Así lo sostiene abiertamente Cane a propósito del ordenamiento jurídico de inglés, quien afirma que "al juzgar la razonabilidad de las precauciones que una persona adopta para proteger sus propios intereses, el derecho es más permisivo en relación con la edad, los recursos y las capacidades mentales y físicas que lo que sería tratándose de la negligencia generadora de responsabilidad". CANE, Peter, Anatomía 
dementes sean responsables frente a terceros, pero a su respecto no pueda invocarse la culpa concurrente ${ }^{54}$. Una idea semejante ha sido propuesta en Francia, donde un sector de la doctrina ha propuesto reservar la noción de culpa objetiva en la responsabilidad para con los demás y aplicar la noción de culpa subjetiva a los carentes de discernimiento ${ }^{55}$. Estimamos que esta solución atenta contra el principio de igualdad en las relaciones y con la necesidad jurídica de que las personas se comporten como lo haría un hombre razonable en todas las circunstancias de la vida, de ahí que nos parezca más justa la llamada "regla del espejo", esto es, que la conducta de la víctima sea considerada causa concurrente del daño sólo cuando, en las mismas circunstancias, estaría obligada a indemnizar si un tercero fuera la víctima ${ }^{56}$. De esta manera, no resulta procedente aplicar la regla del artículo 2330 a las víctimas que, según el artículo 2319, son incapaces de incurrir en culpa.

Establecido que a las víctimas incapaces de responder civilmente no se les puede oponer la culpa concurrente propia, surge la necesidad de analizar qué pasa en aquellos casos en que la víctima incapaz ha sufrido el accidente como consecuencia de la culpa concurrente de quienes tenían el deber de cuidarla. Por ejemplo, un menor de cuatro años es llevado por sus padres al zoológico y en un descuido de los padres el menor se introduce en la jaula de un gorila ${ }^{57}$. En tales casos, aunque sea por unos pocos instantes de descuido, salta a la vista (res ipsa loquitur) que los padres han infringido su deber de cuidado y, por tanto, son copartícipes del eventual daño que el gorila cause al menor. Según lo dicho precedentemente, si los padres deciden demandar el daño moral propio, el juez podrá aplicar desde luego

del derecho de daños (Traducc. Daniel Arturo Carvallo Montes, et al., Santiago, Flandes Indiano, 2011) p. 97.

${ }^{54}$ Esta es la regla en el Common Law estadounidense vid Terry, Henry T., Negligence, en Harvard Law Review 29 (1915) 1, p. 47; Zeno-ZenCovich, Vincenzo, La colpa oggettiva del malato di mente: le esperienze nor-americane e francese, en Responsabilità civile e previdenza 51 (1986), p. 8; YÁÑEZ VIVERO, Fátima, La experiencia del Civil Law y del Common Law en el ámbito de la responsabilidad civil de las personas incapaces, en Boletín mexicano de derecho comparado 132 (2011), p. 1315.

55 BACACHE-GiBEILI, Mireille Les obligations. La responsabilité civile extracontractuelle (Paris, Editorial Económica, 2007), pp. 127 ss.

56 Martín-Casals, Miquel, A través del espejo: concurrencia de "culpa" de la víctima y culpa del causante del daño, en AA. VV. Estudios jurídicos en homenaje al profesor Luis Diez-Picazo (Madrid, Editorial Thomson Civitas, 2003), pp. 2471-2490; Martín-Casals, Miquel (editor), Children in Tort Law. Part II: Children as Victims (Viena, Springer, 2007), passim.

57 El caso corresponde a un famoso episodio ocurrido recientemente en Estados Unidos, donde las autoridades del zoológico sacrificaron al gorila, por salvar al niño. 
el artículo 2330; empero, surge la pregunta ¿qué pasa respecto del daño demandado por los padres en representación de la víctima incapaz? En estricto rigor, a esta víctima no es posible aplicar la culpa concurrente (a menos que aceptemos una noción objetiva de culpa), por lo tanto, ella tiene derecho al resarcimiento integral del daño sufrido. Sin embargo, esta idea no siempre ha sido seguida por la jurisprudencia nacional, que, cuando menos en dos casos, ha utilizado la culpa del cuidador de la víctima como presupuesto para reducir la indemnización de ésta última.

El primero de los casos referidos, se trata del caso de un niño de tres años que cae de un bus en movimiento, en el cual se encontraba con sus dos padres. Al momento de fijar la cuantía de la condena, la Corte Suprema sostuvo: "Que, sin perjuicio de haberse establecido como causa determinante del accidente de que se trata, la conducta antirreglamentaria del demandado Bello, no es menos cierto que el descuido de los padres de la víctima es evidente, procediendo, por lo tanto, dar aplicación a la norma del artículo 2330 del Código Civil, disposición que recoge el principio de la igualdad entre las partes que regula las relaciones de derecho privado y que se traduce en que la culpa de la víctima contribuye a la producción del daño o al aumento de su intensidad, aun cuando en el caso el afectado es incapaz, en la medida en que es en los progenitores en quienes la ley deposita el deber de cuidado necesario al respecto, quienes se encontraban presentes al momento de los hechos y a los que debe exigirseles la conducta razonable y prudente que las circunstancias justificaban, es decir, asegurar al menor con el que viajaban en un bus de transporte colectivo -aunque no en sus funciones habituales-. // Que, en dichas condiciones, este Tribunal estima del caso otorgar una suma única y total por concepto de indemnización por el daño moral sufrido por los padres y el menor afectado, ascendente a $\$ 4.000 .000$.-, con los reajustes e intereses que se consignaran en lo dispositivo de este fallo" 58 .

El segundo caso aludido se trataba de un niño que había sufrido una lesión el glúteo producto de la concurrencia de culpas del hospital en que había sido atendido y de la mala higiene proporcionada por la madre. En este caso, la Corte Suprema sostuvo: "en este mismo orden de ideas, tampoco es cierto que los sentenciadores hayan elevado a la calidad de causa natural la actuación deficiente de la madre del menor, puesto que ellos sólo le han atribuido la calidad de exposición imprudente al riesgo, procediendo a disminuir el monto de la indemnización conforme al artículo 2330 del Código Civil. Asi, aun cuando esta Corte no comparte tal reducción, -puesto que no se puede sostener que un niño de 3 años se exponga imprudentemente al riesgo, ni tampoco que los actos realizados por un tercero (madre) impliquen una

58 Corte Suprema, 25 de septiembre de 2012, Rol No 9942-2010. 
exposición de la víctima- ella deja de manifiesto un hecho concreto, esto es, que la actuación de la madre jamás ha sido considerada por los sentenciadores como causante del daño, pues sólo la han tomado en consideración para regular el quantum de la indemnización, cuestión que se relaciona directamente con la extensión de los perjuicios y no con la existencia de los mismos" $"$. Al margen de lo criticable del razonamiento, pues niega que la negligencia de la madre haya sido considerada causa del daño, cuando es exactamente lo que ocurre, sin perjuicio de que no sea la única causa, lo relevante del mismo es que él acepta que la culpa de la madre sea utilizada para regular la cuantía de la indemnización del hijo.

Desde el punto de vista de la dogmática de la culpa de la víctima, los fallos anteriores son desde luego criticables, pues la víctima incapaz no puede sufrir las consecuencias de la negligencia de la persona a cuyo cuidado está. Resulta contradictorio con la idea de deber de cuidado impuesto a estas personas que su negligencia pueda ser invocada en desmedro del resarcimiento integral del daño a que tiene derecho la víctima incapaz. Con todo, sin perjuicio de que no se lo diga, los tribunales parecieran tener en consideración el hecho de que quienes actúan en representación de la víctima y, por tanto, quienes recibirán el dinero producto de la indemnización, son las mismas personas cuya negligencia coadyuvó a la producción del daño. En consecuencia, si bien indirectamente, ellas resultarían beneficiadas con la indemnización que se decretara en favor de la víctima y, bajo esta perspectiva, la disminución de esta suma indemnizatoria redunda en una disminución del beneficio que ellas obtendrían, dejando de su cargo una parte del daño ${ }^{60}$.

Así las cosas, aunque en estricto rigor no respete las reglas que gobiernan la culpa de la víctima, desde una perspectiva más general, tales decisiones sí contienen un principio de justa distribución de los costes del accidente, en la medida que la indemnización que se fije a favor de la víctima

59 Corte Suprema, 10 de junio de 2013, Rol No 9554-2012.

${ }^{60}$ Vale la pena señalar que consideraciones semejantes a estas fueron hechas por los tribunales ingleses para negar la indemnización en este tipo de casos. Esta posición es criticada por la doctrina, bajo la idea de que la responsabilidad civil es personal y, bajo el pretexto de que no puede beneficiarse al culpable, no puede perjudicarse a la víctima (vid H.D.S, Torts. Injury to Infants. Negligence of Parents Imputed to Children, en University of Pennsylvania Law Review, 65 (1917) No. 4, pp. 382-385; Cane, Peter, Atiyah's Accidents, Compensation and the Law (8 edición, Cambridge, Cambridge University Press, 2013), pp. 53 ss.). Concordamos con que el beneficio indirecto del concausante del daño no puede ser una razón para que el otro causante quede exento de responsabilidad, pero nos parece que, aplicada correctamente, el método empleado por los tribunales chilenos no es objeto de esa crítica, pues no priva a la víctima, sino que distribuye el daño. 
beneficiará también al concausante del daño, quien recibirá el importe de la misma. En el fondo, el principio que subyace en estas sentencias es el expuesto anteriormente, esto es, que el guardián debe soportar la parte de daño que ha causado a la víctima, pues en esa parte no resulta imputable al demandado. Sin embargo, resulta criticable que las sentencias no se hagan cargo de este argumento y no se ocupen de distinguir exactamente las sumas indemnizatorias que corresponden a uno y otro damnificado, así como la parte que deberá soportar el demandante ${ }^{61}$.

Sentado que la idea subyacente a los fallos reseñados es el hecho de que quien coadyuvó a causar el daño resultará beneficiario (indirecto) de la indemnización que se otorgue a la víctima, resulta que, a contrario sensu, si ésta demanda su indemnización de manera independiente del guardián que coadyuvó en la producción de su daño, la regla contenida en los fallos reseñados no debiera aplicarse y tendrá derecho a la indemnización plena. Tal sería el caso, por ejemplo, si el accidente se produjera mientras la víctima estaba al cuidado de un tercero y demandan los padres ${ }^{62}$, o bien cuando los padres mueren en el accidente o, a raíz de éste, pierden el cuidado del menor y la demanda la ejerce el nuevo cuidador. En todos estos casos, el tercero demandado deberá resarcir íntegramente a la víctima directa, sin perjuicio de una eventual aplicación del artículo 2317, en los términos y con las dificultades antes vistos.

Una última hipótesis un tanto más discutible, se presenta en el caso en que quien contribuye a la lesión del incapaz es un miembro de la familia que no participa del juicio de responsabilidad civil, ni como demandante del daño propio, ni en representación del incapaz, por ejemplo, un abuelo. Estimamos que, en este caso, al igual que el caso en que el caso anterior, debería darse una indemnización integral a la víctima incapaz, pues no puede traspasarse la negligencia de un tercero a la víctima incapaz, sin perjuicio de la posible acción de repetición.

${ }^{61}$ Con todo, esta es una crítica transversal a las sentencias que aplican el artículo 2330, pues ninguna de ellas se preocupa de establecer claramente la cuantía de la reducción, ni de señalar los criterios sobre la base de los cuales ha sido calculada. Sin embargo, el análisis de esta crítica excede con creces los propósitos de este trabajo y, por tanto, será objeto de otra publicación.

${ }^{62}$ Evidentemente, para que tenga lugar lo aquí dicho debe tratarse de un tercero que no tenga una relación contractual con los padres, podría ser, por ejemplo, un jardín infantil público, o bien, un hospital y que, en esas circunstancias, un tercero cause un daño al menor. Si bien lo más probable es que se decida demandar al recinto educacional u hospitalario, también podría intentarse la acción contra el tercero y, de ser así, surgiría el problema aquí reseñado. 


\section{OBSERVACIONES FINALES}

A modo de conclusión, del análisis efectuado en las páginas precedentes se desprende que, si bien existe un amplio consenso doctrinario en el sentido que la culpa de la víctima directa es oponible a la víctima indirecta, la falta de un análisis dogmático, que desprenda tal conclusión de los elementos de la responsabilidad civil, ha impedido la uniformidad jurisprudencial, a pesar a de una clara tendencia en ese sentido.

Por nuestra parte, estimamos que la justificación de tal oponibilidad se funda precisamente en el elemento causalidad, en la medida que la víctima directa es concausa del daño por rebote, al agente no resulta imputable todo el daño sufrido por la víctima indirecta, sino sólo una parte. Adicionalmente, cabe señalar que la víctima por rebote no tiene acción para reclamar de la víctima directa el daño sufrido por ella, pues, en esa parte, el daño no resulta de la infracción de un deber de cuidado, sino sólo de una carga, que se caracteriza precisamente porque no da lugar a exigibilidad de la conducta, ni tampoco a responsabilidad por los eventuales perjuicios que un tercero sufra a consecuencia a de su inobservancia. Esta circunstancia es muy relevante, toda vez que permite excluir la solidaridad derivada del artículo 2317; es decir, incluso desde la perspectiva de la obligación a la deuda, el agente sólo debe la parte del daño que le resulta jurídicamente imputable, sin que pueda ser obligado al resarcimiento integral del daño. Así las cosas, al fijar la cuantía de la indemnización debida a la víctima por rebote, el juez deberá considerar la culpa concurrente de la víctima directa y rebajar la indemnización según las reglas que gobiernan la reducción del resarcimiento por culpa concurrente de la víctima, que por motivos de extensión y contenido no pueden ser abordadas en este texto.

Por otro lado, la relación entre culpa de la víctima y daño por repercusión se evidencia en otras hipótesis, esto es, cuando la víctima que sufre el daño es incapaz y, por tanto, está sujeta al cuidado de una persona, cuya negligencia contribuye a la producción del daño. En estos casos, los problemas que se ponen son de variada índole, en especial, el hecho de que el guardián puede demandar una indemnización a título personal y, además, en su calidad de representante de la víctima. Tratándose del daño que solicita para sí mismo, resulta meridianamente claro que al guardián resulta aplicable el artículo 2330, pero no resulta claro si esta culpa es apta para rebajar el daño sufrido por el incapaz. La jurisprudencia nacional en algunos casos ha entendido que sí, pero no se ha ocupado de detallar la solución. Por nuestra parte, entendemos que estas soluciones jurisprudenciales se fundan en el hecho de que quienes demandan la indemnización, en calidad de representantes de la víctima, son también quienes han contribuido a su 
daño y, desde esta perspectiva, la solución no resulta tan descabellada. Sin embargo, no puede tratarse de una solución generalizada, en la medida que, si la víctima incapaz actúa independientemente de quien coadyuvó en la producción de su daño, merece una indemnización integral.

Otro problema relacionado con lo anterior, es el caso en que, además del guardián, existen otras víctimas por rebote, que no han participado en la producción del accidente. En tal caso, si todas las víctimas por rebote, incluido el guardián, son conjuntamente demandantes, no se ve obstáculo para que el juez considere la negligencia de éste y le obligue a soportar parcialmente el daño sufrido por las demás víctimas, a través de la rebaja de su propia indemnización. Sin embargo, el panorama no resulta tan claro cuando quienes demandan son víctimas por rebote distintas del guardián y este no ha tomado parte en el juicio, pues en tal caso es necesario determinar la suerte del artículo 2317 en la materia, cuestión que escapa a los objetivos de este trabajo, pues no existen estudios sobre la operatividad práctica de esta norma.

\section{BibLIOGRAFíA}

Alessandri Rodríguez, Arturo, De la responsabilidad extracontractual en el derecho chileno (Santiago, Imprenta Universitaria, 1943).

BaCACHE-Gibeili, Mireille, Les obligations. La responsabilité civile extracontractuelle, (Paris, Editorial Económica, 2007).

Bahamondes O. Claudia - Pizarro W., Carlos, La exposición imprudente de la víctima al daño desde la culpabilidad a la causalidad, en Revista de Derecho de la Pontificia Universidad Católica de Valparaíso, No XXXIX ( 2012).

Barros Bourie, Enrique, Tratado de responsabilidad extracontractual (Santiago, Editorial Jurídica de Chile, 2006).

BetTi, Emilio, Teoria generale del negozio giuridico (reimpresión corregida de la $2^{\text {a }}$ ed., al cuidado de Giuliano Crifó, Napoli, Edizioni Scientifiche Italiane, 2002).

Bianca, C. Massimo, Diritto Civile 5. La responsabilità (Milán, Giuffrè, 2004).

CABANILla SÁNCHEZ, Antonio, Las cargas del acreedor en el derecho civily en el mercantil (Madrid, Montecorvo, 1988).

Cane, Peter, Anatomía del derecho de daños (Traducc. Daniel Arturo Carvallo Montes, et al., Santiago, Flandes Indiano, 2011)

Cane, Peter, Atiyah's Accidents, Compensation and the Law ( $8^{\mathrm{a}}$ edición, Cambridge, Cambridge University Press, 2013).

CHABAS, François, L'influence de la pluralitè de causes sur le droit a réparation, París, L.G.D.J., 1967.

Corral Talciani, Hernán, Lecciones de responsabilidad extracontractual (2a ed., Santiago, LegalPublishing, 2013).

Díez SChwerter, José Luis, El daño extracontractual (Santiago, Editorial Jurídica de Chile, 1997).

Díez SCHWERTER, José Luis, Víctimas indirectas y por repercusión en la responsabilidad civil derivada de accidentes del trabajo o enfermedades profesionales en nuestra juris- 
prudencia reciente: del problema de la competencia a las distorsiones sustanciales, en Revista de Derecho - Universidad de Concepción 214 (2003).

Di Majo, Adolfo, Obligazione solidali (e indivisibili), en Enciclopedia del Diritto, vol. XXIX (Milán, Giuffrè, 1979).

Domínguez Águila, Ramón, Aspectos de la relación de causalidad en la responsabilidad civil con especial referencia al Derecho chileno, en Revista de Derecho Universidad de Concepción, 209 (2001).

Domínguez Águila, Ramón, El hecho de la víctima como causal de exoneración de responsabilidad civil, en Revista de Derecho Universidad de Concepción, 136 (1966).

Domínguez Águila, Ramón, Inaplicabilidad de la responsabilidad subsidiaria laboral en la acción extracontractual civil. Inoponibilidad de la culpa de la victima a las víctimas por repercusión o rebote, en Revista de Derecho Universidad de Concepción, 215-216 (2004).

Domínguez Águila, Ramón, La culpa en el derecho civil chileno. Aspectos generales, en Revista Anales Derecho UC, 3, (2008).

Domínguez Águila, Ramón, Los límites al principio de reparación integral, en Revista chilena de derecho privado 15 (2010).

Elorriaga De Bonis, Fabián, El daño por repercusión o rebote, en Revista Chilena de Derecho 26 (1999) 2.

ELORRIAGA DE BONIS, Fabían. Novedades judiciales en torno al daño moral por repercusión, en Corral Talciani, Hernán y Rodríguez Pinto, María Sara (coordinadores), Estudios de derecho civil II (Santiago, AbeledoPerrot - LegalPublishing, 2007).

Escribar Mandiola, Héctor, Responsabilidad civil sin culpa, en Revista de Derecho y Jurisprudencia, 20, (1923).

European Group on Tort Law, Principles of European Tort Law. Text and Commentary (Viena, Sprimger, 2005).

FERnÁNDEZ CRUZ, Gastón, De la culpa ética a la responsabilidad subjetiva: ¿el mito de Sísifo? (panorámica del concepto y del rol de la culpa en el derecho continental y en el Código Civil peruano), en Revista Themis, 50, (2005).

Franzoni, Massimo, Fatti illeciti. Commentario del Codice Civile Scialoja-Branca. Obligazioni art. 2043-2059 (Bolonia, Zanichelli, 1993).

Gnani, Alessandro, La responsabilità solidale. Art. 2055 (Milán, Giuffrè, 2005).

H.D.S, Torts. Injury to Infants. Negligence of Parents Imputed to Children, en University of Pennsylvania Law Review, 65 (1917) No. 4.

KUNKAR ONETO, Andrés, ¿Es el estatuto de la responsabilidad extracontractual aplicable a las víctimas por repercusión o rebote?, en ELORRIAGA DE BONIS, Fabián (coordinador), Estudios de derecho civil VII (Santiago, AbeledoPerrot - Thomson Reuters, 2012).

Magnus, Ulrich, Martín-Casals, Miquel, Unification of Tort Law: Contributory negligence (La Haya, Kluwer International, 2003).

Mantilla Espinosa, Fabricio, Ternera Barrios, Francisco, La noción de culpa en la responsabilidad extracontractual, en Actualidad Jurídica, 11, (2005).

Martín-Casals, Miquel (editor), Children in Tort Law. Part II: Children as Victims (Viena, Springer, 2007).

Martín-Casals, Miquel, A través del espejo: concurrencia de "culpa" de la víctima y culpa del causante del daño, en AA. VV. Estudios jurídicos en homenaje al profesor Luis Diez-Picazo (Madrid, Editorial Thomson Civitas, 2003).

Mazeud, Henri, Mazeud, Léon, Tunc, André, Tratado teórico y práctico de la res- 
ponsabilidad civil, delictualy contractual (Traducc. Luis Alcalá Zamora y Castillo, Buenos Aires, Ediciones Jurídicas Europa-América, 1962).

Pizarro Wilson, Carlos, Mal praxis en el equipo médico, en Revista Médica de Chile, 139 (2011).

ProençA, José Carlos, Brandão, A conduta do lesado como presuposto e criterio de imputação di dano extracontractual (Coimbra, Almedina, 2003).

Roca, Encarna, Derecho de daños, $4^{\text {a }}$ ed. Valencia, Tirant lo Blanch, 2003.

SAN Martín Neira, Lilian C. La culpa de la víctima en la estructura de la responsabilidad civil, en Departamento de Derecho Privado Universidad de Concepción (editor), Estudios de derecho civil XI (Santiago, Thomson Reuters, 2016).

San Martín Neira, Lilian C., La carga del perjudicado de evitar o mitigar el daño (Bogotá, Universidad Externado, 2012).

Terry, Henry T., Negligence, en Harvard Law Review 29 (1915) 1.

VINEY, Geneviève, Tratado de derecho civil. Introducción a la responsabilidad (Traducc. Fernando Montoy Mateus, Bogotá, Editorial Universidad Externado de Colombia, 2007).

Violante, Umberto, La responsabilità parziaria (Napoli, Edizioni Scientifiche Italiane, 2004).

WEGNER A., Verónica, ¿Es verdaderamente la acción de la víctima por repercusión o rebote una acción autónoma e independiente?, en Turner Saelzer, Susan y Varas Braun, Juan Andrés (coordinadores), Estudios de derecho civil IX (Santiago, LegalPublishing - Thomson Reuters, 2014).

Yáñez Vivero, Fátima, La experiencia del Civil Law y del Common Law en el ámbito de la responsabilidad civil de las personas incapaces, en Boletín mexicano de derecho comparado 132 (2011).

Zeno-Zencovich, Vincenzo, La colpa oggettiva del malato di mente: le esperienze noramericane e francese, en Responsabilità civile e previdenza 51 (1986). 
